\title{
THE INFLUENCE OF SHORT-TERM THERMO- MECHANICAL DENSIFICATION ON THE SURFACE WETTABILITY OF WOOD VENEERS
}

\author{
Pavlo Bekhta ${ }^{1, \wedge}$, Tomasz Krystofiak ${ }^{2}$
}

\begin{abstract}
The study investigated the effects of short-term thermo-mechanical (STTM) densification temperature and pressure on changes in surface wettability of alder (Alnus glutinosa), beech (Fagus sylvatica), birch (Betula verrucosa) and pine (Pinus sylvestris) wood veneer. Veneer sheets were densified using pressure levels of $4 \mathrm{MPa}, 8 \mathrm{MPa}$ and $12 \mathrm{MPa}$ at three temperatures: $100^{\circ} \mathrm{C}, 150^{\circ} \mathrm{C}$ and $200^{\circ} \mathrm{C}$ for a short time of $4 \mathrm{~min}$. Wettability was determined by measuring contact angles with distilled water. The results were compared with those of non-densified veneers. The results showed that in a relatively short process time wettability can be changed significantly. The wettability analysis showed that STTM-densified veneer surfaces became more hydrophobic, which indicates poor wettability. However, it was found that even STTM densification of veneers provides stable properties; in particular, contact angle values were stable for 24 hours after densification, which is an important consideration for industrial applications. The effect of temperature on the contact angle was more evident than that of pressure. Linear correlations were found between contact angle and both mass loss and compression ratio for all investigated wood species. These findings may be used to provide initial data for adhesive/ coating application processes in woodworking industry.
\end{abstract}

Keywords: Compression ratio, contact angle, mass loss, short-term thermo-mechanical densification, wettability, wood veneer.

\section{INTRODUCTION}

Wood has several advantageous characteristics when compared with other materials (plastics, metals, etc.). It is visually attractive with good color and texture, it may be easily glued, painted/ coated, and joined, etc. However, as a material of organic origin, wood is exposed to degradation under the influence of envoronmental factors: water, light, fire and microorganisms. Very often to eliminate negative properties wood is modified, glued to produce wood-based materials or decorated. As glue or paint is applied to the wood surface before gluing/finishing, physical and chemical properties of the surface of connecting materials are very important. Furthermore, information about surface properties can be used to assess changes in the chemical composition of the surface after different treatment procedures.

\footnotetext{
${ }^{1}$ National University of Forestry and Wood Technology of Ukraine, Department of Wood-Based Composites, Lviv, Ukraine.

${ }^{2}$ Poznan University of Life Sciences, Department of Gluing and Finishing of Wood, Poznan, Poland.

•Corresponding author: bekhta@ukr.net

Received: 29.01.2015 Accepted: 07.10.2015
} 
Wettability is one of these surface characteristics (color, gloss, roughness, wettability) of wood, which significantly affect the process of gluing/coating. Wettability of wood is the ability of a liquid (water, glue, dye, paint) to establish close contact with wood surface. Thus it is a prerequisite for adhesion between the substrate and the adhesive/coating. Wettability is determined by many factors, including wood macroscopic properties (e.g. porosity, surface roughness, surface polarity of wood, pH, moisture contact, direction of fibers, extractives) (Hse 1972, Hse and Kuo 1988, Lu and Wu 2006, Scheikl and Dunky 1998, Shupe et al. 1998, Walinder and Johansson 2001), quality of wood surface (e.g. ageing, contamination) (Gindl et al. 2004, Nguyen and Johns 1979), drying temperature (Casilla et al. 1981, Sernek et al. 2004), properties of adhesives (Hse 1972, Stehr et al. 2001), and set parameters of the mechanical (de Moura and Hernandez 2005, Liptakova et al. 1995, Sinn et al. 2004, Stehr et al. 2001) or thermal treatment (Hakkou et al. 2005, Unsal et al. 2011) or the viscoelastic thermal compression (VTC) process (Kutnar et al. 2008). From these studies it results that: 1) earlywood shows better wettability and consequently better adhesion than latewood; 2) penetration mainly depends on the size of molecules and viscosity of the adhesive; 3 ) wettability of wood surface strongly depends on its roughness; an increase in surface wettability is often associated with an increase in surface roughness; 4) contact angle decreases with time and increases with rises of drying temperature; 5) heat treatment of wood increases hydrophobicity of surfaces, resulting in a decrease in wettability; 6) mechanical surface treatment alters morphological properties and chemical composition of the wood surface; 7) solventextraction of wood surfaces improves their wettability; 8) wood extractible compounds are responsible for poor wettability; the presence of extractives decreases wettability of wood surfaces; 9) wettability of wood surfaces decreases with ageing of the surface; 10) the VTC process of solid wood degrades wettability of its surface and lowers surface energetics and polarity of wood; and 11) low contact angles are more important for efficient wettability and adhesion.

Most studies were conducted concerning wettability of solid wood. In contrast, much less research has been conducted on wood veneer (Croitorua et al. 2011, Diouf et al. 2011, Hse 1972, Loh et al. 2011, Lu and Wu 2006, Matuana et al. 1998, Moghaddam et al. 2014, Shupe et al. 1998, Tinh et al. 1977, Vazques et al. 2011, Wei et al. 2012).

The influence of rotary peeling on the different behaviour of tight and loose sides of okume, ayous, poplar, fromager and eucalyptus veneers was studied by Vazques et al. (2011). The presence of lathe checks on the loose sides favours wettability, with the contact angle decreasing more rapidly on these sides than on the tight sides. Additionally, pine bark tannins improved wettability due to their surfactant character. Tinh et al. (1977), found that extraction with methanol-benzene greatly improved wettability and gluability of apitong veneer. A positive linear correlation was found between wettability and gluability of apitong veneer. Moghaddam et al. (2014), investigated wettability properties of wood veneers using a swellable liquid (water) and a non-swellable liquid (octane). Some researchers have suggested chemical modification of wood veneer surfaces by acidic dyestuff and fixing agents (Wei et al. 2012), with different coupling agents (Lu and Wu 2006, Matuana et al. 1998), with low molecular weight phenol formaldehyde resin (Loh et al. 2011), and with four types of imidazolium-based ionic liquids (Croitorua et al. 2011) to improve their interaction with adhesives. The treated wood showed some useful properties, such as improved wettability, that could lead to an increase of wood surface compatibility with polar adhesives or coatings and toa decrease of their specific consumption.

Moreover, in recent years thermo-mechanical (Arruda and Menezzi 2013, Bekhta 2003, Bekhta and Marutzky 2007, Bekhta et al. 2009, 2012) or thermo-hydro-mechanical processing (Diouf et al. 2011, Navi and Sandberg 2012) have been used to improve physical and mechanical properties of wood and wood-based materials. However, this treatment causes changes in surface properties of wood, in particular the surface becomes hydrophobic, which can cause serious problems (even more complicated) when gluing or coating.

Therefore, in literature on the subject there is sufficient information on the influence of different treatments on changes in wettability of wood and wood-based materials. However, most of these studies were performed on solid wood samples during long-term treatment. Nevertheless, not much is known about wettability of wood/veneers densified for a short time. From an anatomical point of view, veneer can be considered as an analogue to solid wood. However, with respect to thickness the compression of veneer, for a particular degree of densification, may be achieved within less time and at lower pressures 
and temperatures than that required for solid wood.

As there are no studies on the impact of STTM-open systems on wettability of wood veneers of various wood species, the objective of the present study was to characterize the effects of STTM densification temperature and pressure on wettability.

\section{MATERIALS AND METHODS}

\section{Wood veneer samples}

Up to now, birch was used as the main raw material for plywood in Ukraine. However, the current situation in the wood market results in the need to find alternative raw materials. In Ukraine apart from birch alder, beech and pine may also be used to produce plywood.

Therefore, rotary-peeled alder (Alnus glutinosa Goertn.), beech (Fagus sylvatica L.), birch (Betula verrucosa Ehrh.) and pine (Pinus sylvestris L.) wood veneers were used in this study. The nominal thickness of the veneers was $1,5 \mathrm{~mm}$. Tangential sheets of veneer were cut into $140 \mathrm{~mm} \times 100 \mathrm{~mm}$ rectangular pieces for thermomechanical densification and subsequent measurements. Veneer sheets without visible defects were selected.

\section{Short-term thermomechanical densification}

Veneer sheets were densified using heat and pressure. Each veneer specimen was STTM densified between smooth and carefully cleaned heated plates of an open-system laboratory press at temperatures of 100,150 or $200^{\circ} \mathrm{C}$ and pressures of 4,8 or $12 \mathrm{MPa}$ for short time of $4 \mathrm{~min}$. After densification, the densified veneer was removed from the press and cooled to room temperature. Afterwards, to reduce any surface aging effects, all produced densified veneer specimens were kept in plastic bags in the absence of light and air during the time between the specimen preparation and contact angle measurements. The moisture content of veneer samples prior and after densification was $\sim 5 \%$ and $\sim 1,5 \%$ respectively.

\section{Mass loss of wood and moisture}

Each sample of veneer was weighed before and immediately after STTM densification. Mass loss (ML) of wood and moisture after STTM densification was estimated according to the formula:

$$
M L=\left(\left(m_{0}-m_{1}\right) / m_{0}\right) \times 100(\%),
$$

where $\mathrm{m}_{0}$ is the initial mass of the veneer sample before densification and $\mathrm{m}_{1}$ the mass of the same sample after densification.

Therefore, the mass loss calculated in this study was showing both the mass loss of wood and mass loss of moisture. Usually, to determine only the wood mass loss the specimens would need to be dried to absolute dry condition before and after densification. But it is essential to determine the contact angle and mass loss on the same samples before and after densification, because surface characteristics of samples can be strongly changed by re-drying. In addition, it allows us to find out whether there is a correlation between the contact angle and mass loss.

\section{Static contact angle measurement}

Contact angles of each non-densified and densified sample were measured using the sessile drop method. For each sample five drops of 3,5 $\mu \mathrm{l}$ distilled water were deposited manually, by means of a chromatographic syringe, on the wood tangential surface at different locations; the contact angles were then measured. The contact angle was measured using a microscope equipped with a goniometric head so that the hairline passed through the point of contact between the drop and veneer surface and tangentially to the drop at that location. Measurements were made $5 \mathrm{~s}$ after distilled water was dropped 
to allow the drop to attain equilibrium on the sample surface. To study the potential ageing of densified surfaces contact angle measurements were also performed at 1, 4 and 24 hours after densification. No fewer than five measurements were taken to reduce uncertainty in the measured contact angles due to structural and chemical variations of the wood samples.

\section{Statistical analysis}

For each species ANOVA was conducted to study the effect of densification temperature and pressure on the contact angle and mass loss of the densified veneer at a 0,05 significance level. Duncan's multiple range tests were conducted for multiple comparisons between the means of the measured properties at different temperatures and pressures for each wood species.

\section{RESULTS AND DISCUSSION}

\section{Mass loss}

Mass losses for each investigated wood species from 100 to $200^{\circ} \mathrm{C}$ at different pressures are presented in Figure 1. Our results showed that mass loss increased with an increasing densification temperature and pressure which is in agreement with earlier studies (Baysal et al. 2014, Pétrissans et al. 2014). ML is more affected by densification temperature than by densification pressure irrespective of the investigated wood species (Table 1).

Table 1. ANOVA for contact angle and mass loss of densified wood veneers.

\begin{tabular}{cccccc}
\hline \multirow{2}{*}{$\begin{array}{c}\text { Wood } \\
\text { species }\end{array}$} & \multirow{2}{*}{ Source } & \multicolumn{2}{c}{ Contact angle } & \multicolumn{2}{c}{ Mass loss } \\
\cline { 3 - 6 } Alder & Temperature & F-ratio & p-value & F-ratio & p-value \\
& Pressure & 165,381 & 0,000 & 902,526 & 0,000 \\
& Temperature $\times$ Pressure & 18,714 & 0,000 & 6,107 & 0,005 \\
\multirow{3}{*}{ Beech } & Temperature & 593,925 & 0,000 & 2,736 & 0,044 \\
& Pressure & 58,532 & 0,000 & 1530,361 & 0,000 \\
& Temperature $\times$ Pressure & 20,897 & 0,000 & 0,651 & 0,527 \\
\multirow{3}{*}{ Birch } & Temperature & 271,193 & 0,000 & 0,115 & 0,976 \\
& Pressure & 5,194 & 0,007 & 2337,562 & 0,000 \\
& Temperature $\times$ Pressure & 4,862 & 0,001 & 2,234 & 0,126 \\
\multirow{2}{*}{ Pine } & Temperature & 11,808 & 0,000 & 1984,847 & 0,040 \\
& Pressure & 1,818 & 0,168 & 0,339 & 0,715 \\
& Temperature $\times$ Pressure & 6,564 & 0,000 & 3,283 & 0,022 \\
\hline
\end{tabular}

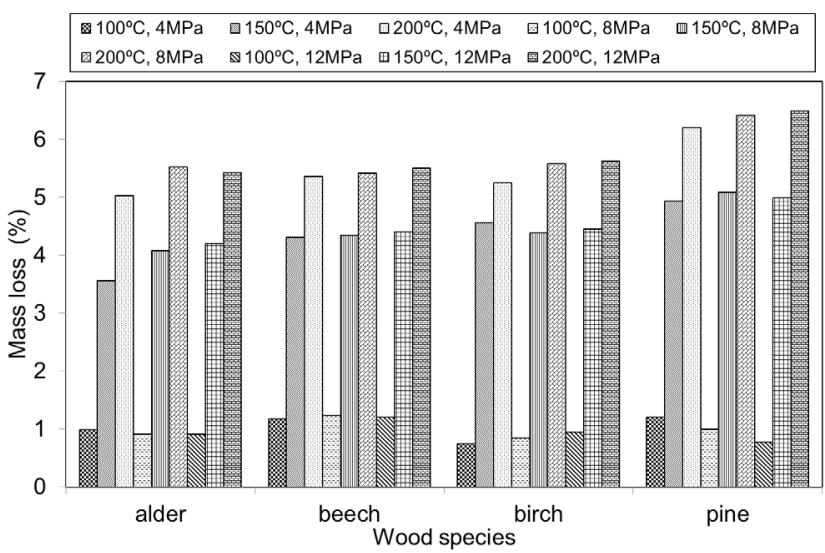

Figure 1. Mass loss of veneer samples during short-term thermo-mechanical densification. 
Mass loss is similar between softwood and hardwoods at equivalent levels of densification, although pine veneer shows slightly higher levels of ML at any given combination of pressures and higher temperatures $\left(150\right.$ or $\left.200^{\circ} \mathrm{C}\right)$ than hardwoods. The opposite results were obtained by Pétrissans et al. (2014); they showed that hardwoods were to be more sensitive to thermodegradation than softwoods, which can be explained by the different conditions of heat treatment. At $100^{\circ} \mathrm{C}$ mass loss is not high and it can be mainly attributed to the thermal loss of water. After this temperature the samples lost very rapidly a certain percentage of their mass (about $6 \%$ at $200^{\circ} \mathrm{C}$ ), particularly in the case of pine veneer. Mass losses may be explained by polysaccharide degradation (Alen et al. 2002); it is well known that removal of extractives and destruction of hemicellulose and lignin take place at high temperatures (Hakkou et al. 2005, Esteves et al. 2013). As it was mentioned by Oliveira et al. (2010), vaporization of larger extractive molecules (such as fatty acid esters) takes place at temperatures higher than $150^{\circ} \mathrm{C}$. The results obtained in this study may be explained not only by the elimination of volatile extractives, but also by structural water that is pulled out of the wood surface at higher temperatures $\left(200^{\circ} \mathrm{C}\right)$ (Oliveira et al. 2010). In this case, as it was stated by Kocaefe et al. (2008), the temperature is high enough to degrade hemicelluloses and then reduce the presence of $\mathrm{OH}$ groups in wood cell walls. However, it should be noted that values of mass loss recorded in this study are low. Therefore, based on these results it may be concluded that chemical changes in the short-term thermomechanical densification of wood veneer are minor. Similar results were reported by Rautkari et al. (2010), who using FTIR spectroscopic analysis showed that no significant chemical changes occur during densification using friction.

\section{Wettability}

The macroscopic structure of softwood, such as pine, and hardwoods, such as alder, beech and birch, is different. Furthermore, in addition to their anatomy, the main difference between coniferous and deciduous species is related to their content of hemicelluloses and extractive substances. The question remains if wettability will also be different.

\section{Non-densified veneer}

There is a significant difference in the values of the contact angle between the investigated wood species (Figure 2). This may be attributed to different surface chemistry of each species, different surface roughness and anatomical (morphological) surface structure. The surface of pine was more hydrophobic than that of the other investigated wood species, as indicated by the contact angle being significantly higher for pine samples $(54,19)$ compared with alder $(28,13)$; beech $(24,59)$ and birch veneer $(45,34)$ samples. This result was expected because in comparison to the other investigated wood species (with $0,8-3,8 \%$ ) pine wood contains a higher amount $(4,4-5,6 \%)$ of extractives (Fengel and Wegener 1989), many of which migrate to the surface during veneer drying. Extractives of pine include most of the wood resins, including nonpolar terpenes (Fengel and Wegener 1989), than hardwoods, which extractives are more polar. Moreover, pine wood contains more lignin $(27,2 \%)$ than the other investigated wood species $(19,4-23,9)$ (Fengel and Wegener 1989), which could also contribute to the lower wettability of pine wood surfaces. 


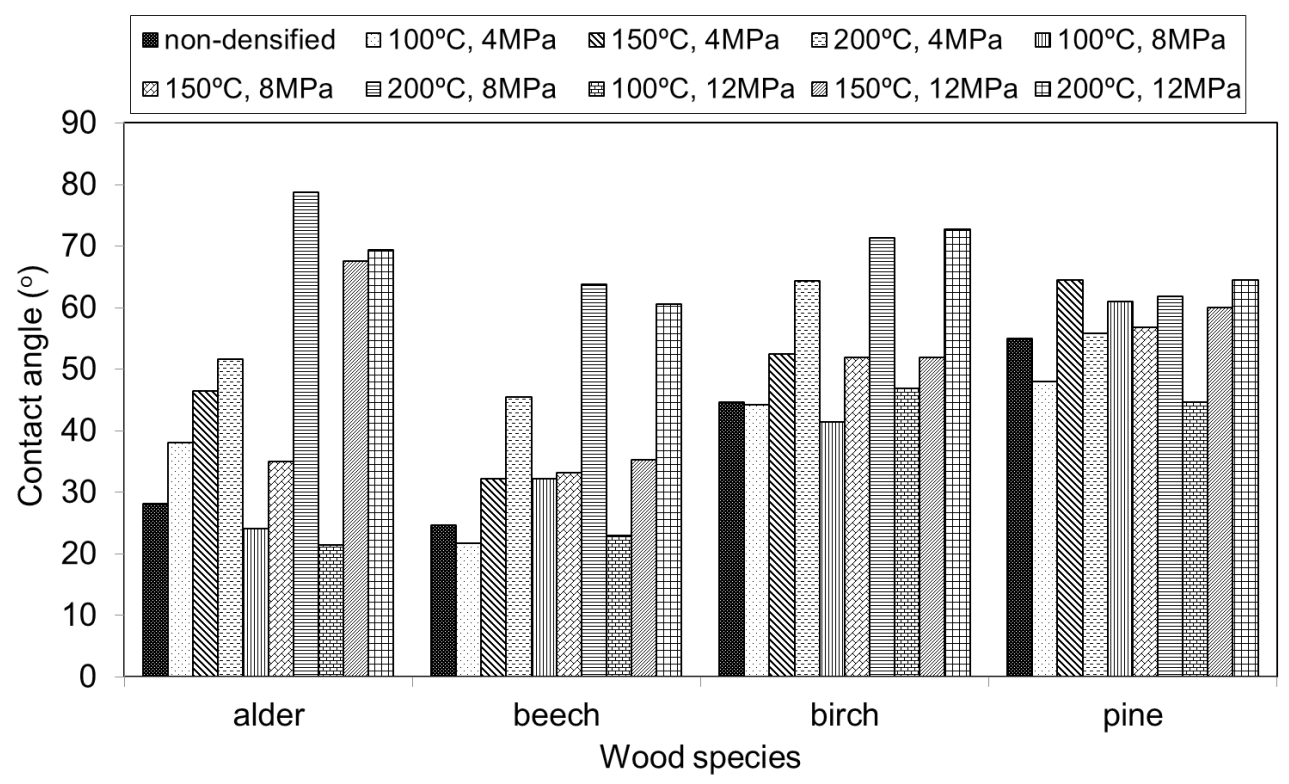

Figure 2. Contact angle changes in veneer samples short-term thermo-mechanically densified at different temperatures and pressures.

\section{Densified veneer}

Physical and chemical processes occur in the layers close to the surface during thermomechanical densification, causing surface modification providing it with new parameters. Figure 2 shows the water contact angle for all investigated wood species at different densification conditions. As expected, the contact angle values of all veneer samples were higher than those of untreated veneer samples; namely densified alder, beech, birch and pine wood veneers showed hydrophobic properties. Somewhat unexpectedly, the contact angles on the densified wood at a low temperature $\left(100^{\circ} \mathrm{C}\right)$ were lower (for some densification conditions) than those of non-densified wood. Perhaps this may be explained by the fact that dehydration of hemicelluloses, lignin and extractives does not occur at a low temperature $\left(100^{\circ} \mathrm{C}\right)$, which is also indicated by mass loss (Figure.1). Besides, this may also be explained by the complex nature of the wood surface, which is a result of the porous structure, surface roughness and chemical heterogeneity of wood. However, the general trend is that the contact angles of the water drop increased with increased densification temperature (except for the temperature of $100^{\circ} \mathrm{C}$ ) and pressure. The ANOVA results revealed that temperature has a more significant effect than pressure on the contact angle (Table 1). The results show that higher temperature leads to a higher contact angle, i.e. worse wetting, for all investigated species. These results are in good agreement with data obtained in earlier studies (Diouf et al. 2011, Kutnar et al. 2008, Unsal et al. 2011).

The highest contact angle was recorded for the surface exposed to $200^{\circ} \mathrm{C}$. In particular, the maximum increase in the contact angle with the temperature increasing to $200^{\circ} \mathrm{C}$ was $179,8 \%$ for alder; $158,7 \%$ for beech and 63,3\% for birch, respectively. However, it should be noted that such a significant change in wettability can have a significant consequence on the use of the material, including serious problems when varnishing or painting (Hakkou et al. 2005). Under similar conditions the increase of the contact angle for pine was only $17,5 \%$. The results are somewhat surprising, as pine had lower values of the contact angle than the other investigated wood for the highest temperature of $200^{\circ} \mathrm{C}$ and densification pressure of $12 \mathrm{MPa}$, having a higher content of extractives and lignin and showing a larger mass loss. 
Obviously, it may be assumed that the content of extractives is not a significant factor that influences wettability. Hardwoods have substantially higher contents of hemicelluloses in comparison with softwoods and hemicelluloses are one of the factors that also have an effect on wettability. Wettability decreases due to chemical changes, such as degradation of the most hygroscopic components of wood (hemicelluloses, lignin and cellulose) (Hakkou et al. 2005, Kocaefe et al. 2008). The degradation of hemicelluloses in wood during heat treatment causes a decrease in the contents of $\mathrm{OH}$ groups and O-acetyl groups, while the subsequent formation of cross-links between wood fibers makes wood more hydrophobic (Kocaefe et al. 2008).

Partial degradation of hemicelluloses and lignin is confirmed by data on mass loss. A close linear positive correlation was found between wettability and mass loss (Figure 3). Wettability deteriorates with an increasing mass loss. A strong linear correlation exists between the contact angle and mass loss for alder $\left(R^{2}=0,80\right)$ and birch $\left(R^{2}=0,73\right)$; while a significant correlation exists for beech $\left(R^{2}=0,63\right)$ and a moderate correlation is found for pine $\left(\mathrm{R}^{2}=0,43\right)$.

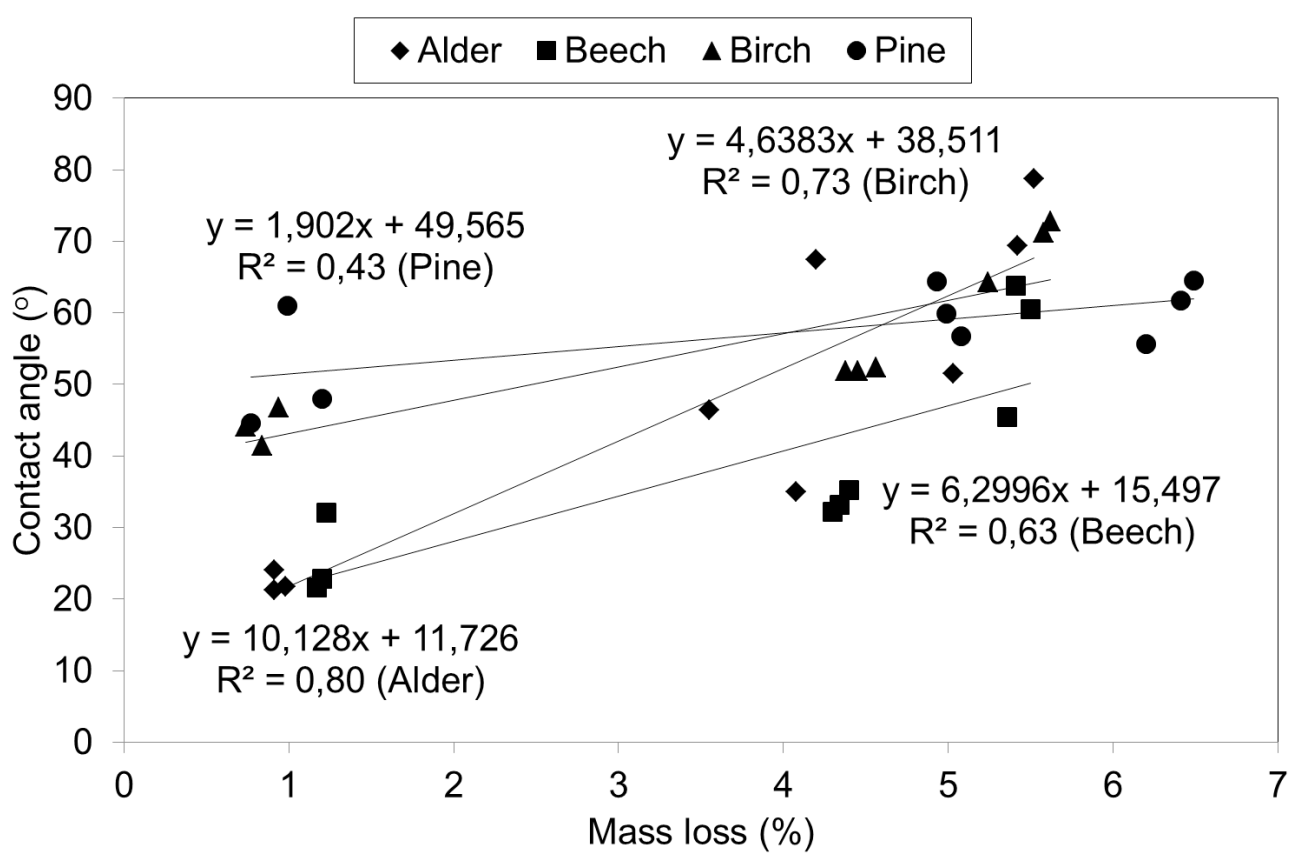

Figure 3. Correlation between contact angle and mass loss.

Thus, it follows from the recorded data on mass loss and the results of previous studies (Diouf et al. 2011, Rautkari et al. 2010), showing no significant chemical changes of wood surfaces during thermomechanical densification, that in addition to the chemical nature of the surface some other surface parameters, in particular roughness, affect wettability. As it was shown in previous study (Bekhta et al. 2014), a smooth surface is formed after thermomechanical densification. It is evident that the wood peeling process produces a highly irregular veneer with a considerable number of crushed and demolished wood cells. In contrast, the pores and microcracks created during peeling and drying were closed during densification. As it was shown, the surfaces of the densified samples were much smoother than those of the non-densified samples, as a result of plasticisation of the veneer surface layers taking place under both high pressures and high temperatures of densification (Bekhta et al. 2012).

Scheikl and Dunky (1998) found that wettability of wood surfaces strongly depends on their roughness. They observed that the contact angle decreases more quickly on rough surface than on the smooth side of veneer and adhesive penetration is also deeper on the rough side than on the smooth side. Surface roughness is closely related to wettability: the higher the roughness, the higher the 
hydrophilicity of the surface (Piao et al. 2010).

Thermo-mechanical densification homogenizes the surface and reduces the impact of anatomical characteristics of wood on the behavior of coating. Thereby, changes in the contact angle on wood surfaces may also be related with morphology. Therefore, it was expected that the contact angles depend on the compression ratio. However, the results showed that the compression ratio has a little or very limited impact on the contact angle of densified wood surface. A possible linear correlation between the contact angle and the compression ratio is presented in figure 4. In particular, significant correlations $\left(R^{2}=0,54-0,58\right)$ were found for alder and beech, a moderate correlation $\left(R^{2}=0,47\right)$ was found for birch, while a weak correlation $\left(\mathrm{R}^{2}=0,14\right)$ was found for pine.

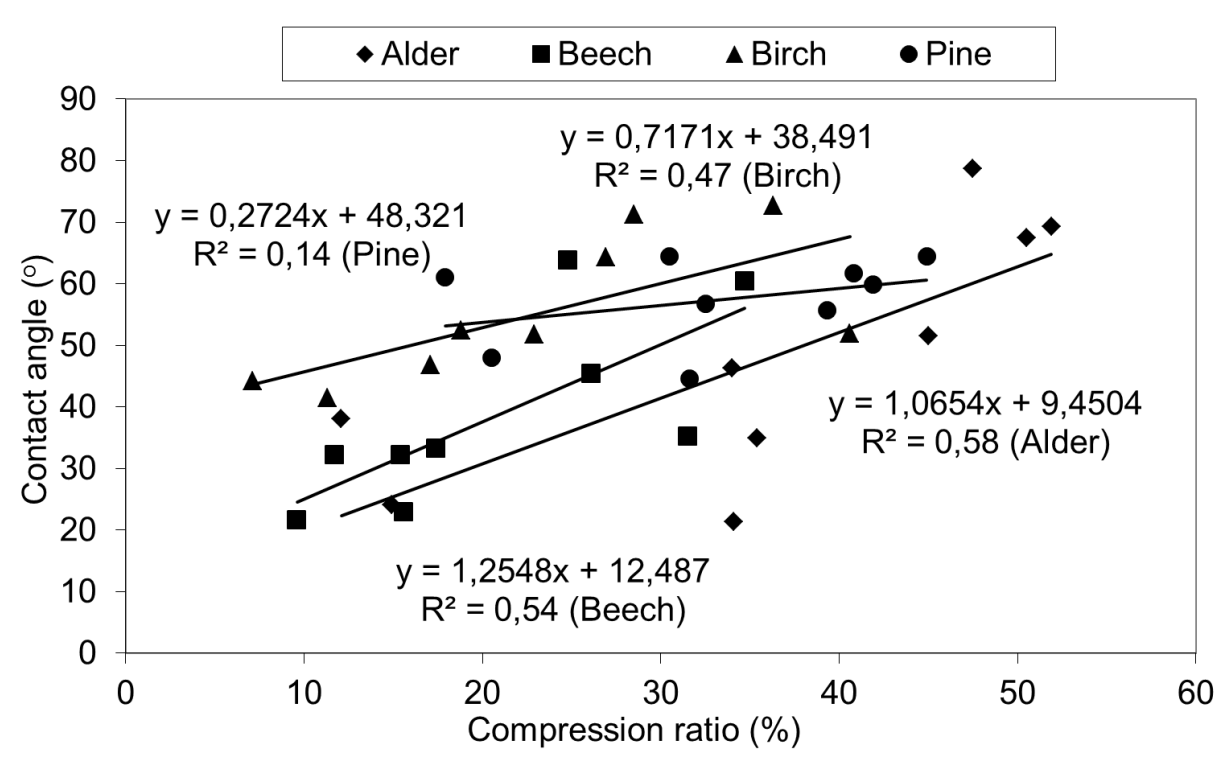

Figure 4. Correlation between contact angle and compression ratio.

The results of Duncan's tests conducted to determine the significance of the relationships between wood species, densification temperature and pressure and the contact angle are given in table 2 .

Table 2. Duncan's test results for main effects.

\begin{tabular}{|c|c|c|c|c|c|c|c|c|}
\hline & \multicolumn{8}{|c|}{ Contact angle $\left({ }^{\circ}\right)$} \\
\hline & \multicolumn{2}{|l|}{ Alder } & \multicolumn{2}{|l|}{ Beech } & \multicolumn{2}{|c|}{ Birch } & \multicolumn{2}{|l|}{$\begin{array}{l}\text { Pine } \\
\end{array}$} \\
\hline & Mean & SG & Mean & SG & Mean & SG & Mean & SG \\
\hline Wood species & 38,84 & $b$ & 31,79 & $a$ & 50,07 & $c$ & 56,19 & $d$ \\
\hline Temperature: & & & & & & & & \\
\hline control & 28,13 & $b$ & 24,65 & $a$ & 44,55 & $a$ & 54,86 & $a$ \\
\hline $100^{\circ} \mathrm{C}$ & 22,36 & $a$ & 25,54 & $a$ & 44,09 & $a$ & 51,19 & $a$ \\
\hline $150^{\circ} \mathrm{C}$ & 49,59 & $c$ & 33,52 & $b$ & 52,05 & $b$ & 60,37 & $b$ \\
\hline $200^{\circ} \mathrm{C}$ & 66,53 & $d$ & 56,54 & $c$ & 69,40 & $c$ & 60,63 & $b$ \\
\hline Pressure: & & & & & & & & \\
\hline control & 28,13 & $a$ & 24,65 & $a$ & 44,55 & $a$ & 54,86 & $a$ \\
\hline $4 \mathrm{MPa}$ & 39,87 & $b$ & 33,06 & $b$ & 53,60 & $b$ & 56,02 & $a b$ \\
\hline $8 \mathrm{MPa}$ & 45,92 & $c$ & 43,03 & $d$ & 54,82 & $b$ & 59,82 & $b$ \\
\hline $12 \mathrm{MPa}$ & 52,70 & $d$ & 39,51 & $c$ & 57,13 & $c$ & 56,34 & $a b$ \\
\hline
\end{tabular}

*SG - statistical group

**Different letters denote a significant difference 
As wood is a heterogeneous material with different chemical compositions, there may be great variation in the results for different species. As it is shown in table 2, differences in the contact angle between all the four wood species were statistically significant; with the ranking of the species by contact angle from the highest to lowest being pine, birch, alder and beech. The effect of densification temperature on the contact angle was statistically significant, with the highest value recorded at a temperature of $200^{\circ} \mathrm{C}$ and the lowest at $100^{\circ} \mathrm{C}$. The effect of densification pressure on the contact angle was also statistically significant, with the highest value recorded at $12 \mathrm{MPa}$ and the lowest obtained for non-densified (control) samples. However, no significant differences were found betweenvarious pressure levels. This change of wettability could have significant consequences on the use of densified veneer, in particular the adhesion of paints and coatings. For example, STTM-densified veneers could be less suitable than non-densified veneers for use with waterborne adhesives and finishing products.

The ANOVA results also showed (Table 3) that the duration of exposure of densified veneer samples does not affect the contact angle of the veneer. Examination of the contact angle decay curves for a 24-h period confirmed that the effect of the densification treatment was stable for at least $24 \mathrm{~h}$ in the case of the hardwood and softwood veneer samples (Figure 5).

Table 3. ANOVA for contact angle with time.

\begin{tabular}{lcc}
\hline Source & F-ratio & p-value \\
\hline Species & 13,277 & 0,000 \\
Time & 0,583 & 0,627 \\
Species $\times$ Time & 0,023 & 1,000 \\
\hline
\end{tabular}

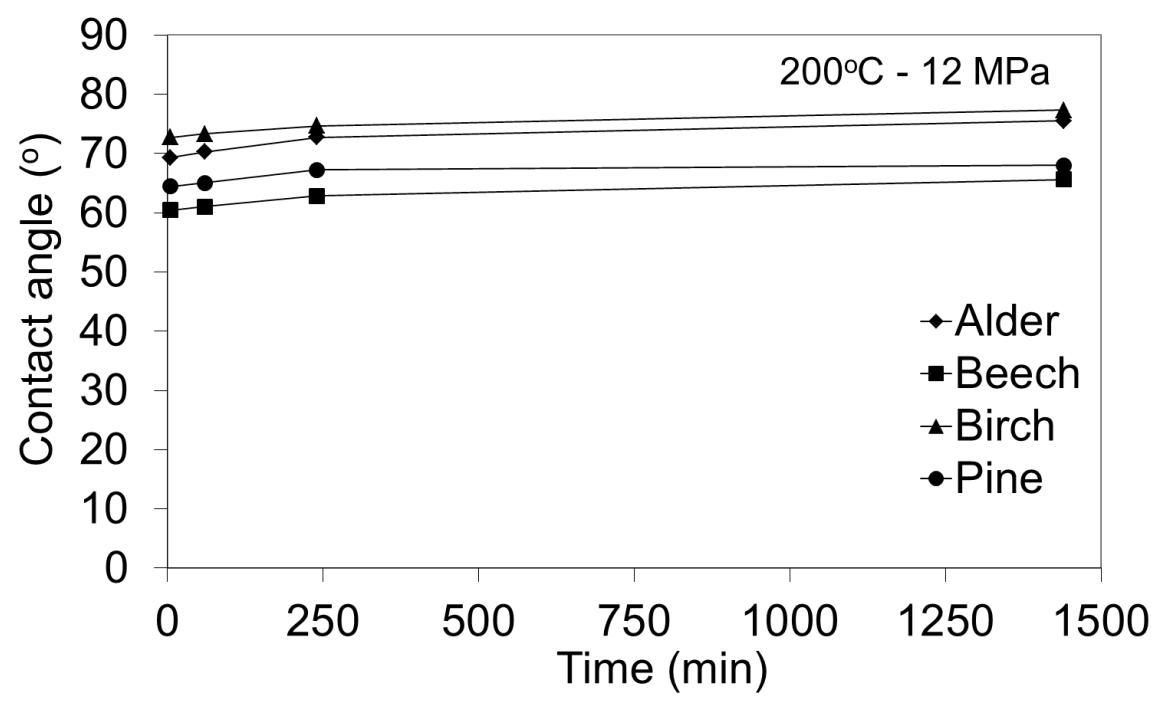

Figure 5. Stability of water contact angle with time.

Based on these results it may be argued that the content of extractives on wood surfaces does not increase after 24-h exposure to air. Therefore, although it is usually considered that ageing affects wettability due to an increase in extractives on wood surfaces, due to various mechanisms such as migration and reorientation (Christiansen 1990), our results did not confirm this hypothesis. Similarly to our findings, Troughton and Chow (1971) observed that the amount of total fatty acids plays a minor role in surface inactivation of white spruce veneer, while Hemingway (1969) reported that the amount of fatty acids in birch did not explain the reduction in its wettability. 


\section{CONCLUSIONS}

The wettability analysis showed that STTM-densified veneer surfaces became more hydrophobic for all of the investigated wood species at temperatures between $150^{\circ} \mathrm{C}$ and $200^{\circ} \mathrm{C}$. The increase in the contact angle on the surface of thermo-mechanically densified wood samples is obviously a result of the hydrothermal treatment caused during densification. The effect of temperature on the contact angle was more evident than that of pressure. The differences in the contact angle between all the four wood species were statistically significant. The wood species were ranked by contact angle from highest to lowest: pine, birch, alder and beech. Based on the data on mass loss of veneer samples, it may be concluded that chemical changes in veneers thermo-mechanically densified for a short time are minor. Linear correlations were found between the contact angle and mass loss and compression ratio for all investigated wood species. A better linear correlation was found between contact angle and mass loss. Values of the coefficients of determination showed that there is no single dominant influence of one factor (mass loss or compression ratio) on wettability. Each of these two factors (mass loss or compression ratio), which is responsible for chemical and morphological changes of the surface brings its share of changes in wettability. The data generated in this study may be used as initial information for further processes such as finishing or gluing of veneer from the four wood species.

\section{ACKNOWLEDGEMENTS}

The authors would like to thank the COST Action FP 1006 "Bringing new functions to wood through surface modification" for financial support within the framework of the Short Term Scientific Mission (STSM).

\section{REFERENCES}

Alen, R.; Kotilainen, R.; Zaman, A. 2002. Themochemical behaviour of Norway spruce (Picea abies) at $180-225^{\circ} \mathrm{C}$. Wood Sci and Technol 36: 163-171.

Arruda, L.; Menezzi, CHS Del. 2013. Effect of thermomechanical treatment on physical properties of wood veneers. International Wood Products Journal 4(4): 217-224.

Baysal, E.; Kart, S.; Toker, H.; Degirmentepe, S. 2014. Some physical characteristics of thermally modified oriental- beech wood. Maderas-Cienc Tecnol 16(3): 291-298.

Bekhta, P.A. 2003. Method of the plywood production. Patent of Ukraine, $\mathrm{N}^{\circ}$ 62787A dated 15.12.03. Bulletin $\mathrm{N}^{\circ} 12$.

Bekhta, P.A.; Hiziroglu, S.; Shepelyuk, O. 2009. Properties of plywood manufactured from compressed veneer as building material. Mater Des 30: 947-953.

Bekhta, P.A.; Marutzky, R. 2007. Reduction of glue consumption in the plywood production by using previously compressed veneer. Holz Roh- Werkst 65: 87-88.

Bekhta, P.A.; Niemz, P.; Sedliacik, J. 2012. Effect of pre-pressing of veneer on the glueability and properties of veneer-based products. Eur J Wood Prod 70(1): 99-106.

Bekhta, P.A.; Proszyk, S.; Krystofiak, T.; Mamonova, M.; Pinkowski, G.; Lis, B. 2014. Effect of thermomechanical densification on surface roughness of wood veneers. Wood Material Science and Engineering 9(4): 233-245.

Casilla, R.C.; Chow, S.; Steiner, P.R. 1981. An immersion technique for studying wood wettability. Wood Sci Technol 15: 3-43. 
Christiansen, A.W. 1990. How overdrying wood reduces its bonding to phenol- formaldehyde adhesives: a critical review of the literature. Part I. Physical responses. Wood Fiber Sci 22(4): 441-459.

Croitorua, C.; Patachia, S.; Cretu, N.; Boer, A.; Friedrich, C. 2011. Influence of ionic liquids on the surface properties of poplar veneers. Appl Surf Sci 257: 6220-6225.

Diouf, P.N.; Stevanovic, T.; Cloutier, A.; Fang, C-H.; Blanchet, P.; Koubaa, A.; Mariotti, N. 2011. Effects of thermo-hygro-mechanical densification on the surface characteristics of trembling aspen and hybrid poplar wood veneers. Appl Sur Sci 257: 3558-3564.

Esteves, B.; Marques, V.; Domingos, A.; Pereira, H. 2013. Chemical changes of heat treated pine and eucalypt wood monitored by FTIR. Maderas-Cienc Tecnol 15(2): 245-258. Berlin.

Fengel, D.; Wegener, G. 1989. Wood: Chemistry, Ultrastructure, Reactions. Walter de Gruyter,

Gindl, M.; Reiterer, A.; Sinn, G.; Stanzl-Tschegg, S.E. 2004. Effects of surface ageing on wettability, surface chemistry, and adhesion of wood. Holz Roh-Werkst 62(4): 273-280.

Hakkou, M.; Pétrissans, M.; Zoulalian, A.; Gérardin, P. 2005. Investigation of wood wettability changes during heat treatment on the basis of chemical analysis. Polym Degrad Stabil 89(1): 1-5.

Hemingway, R.W. 1969. Thermal instability of fats relative to surface wettability of yellow birch wood (Betula lutea). Tappi J 52(11): 2149-2155.

Hse, C.Y.; Kuo, M.I. 1988. Influence of extractives on wood gluing and finishing - a review. For Prod J 38(1): 52-56.

Hse, C.Y. 1972. Wettability of southern pine veneer by phenol formaldehyde wood adhesives. For Prod J 22(1): 51-56.

Kocaefe, D.; Poncsak, S.; Doré, G.; Younsi, R. 2008. Effect of heat treatment on the wettability of white ash and soft maple by water. Holz Roh- Werkst 66: 355-361.

Kutnar, A.; Kamke, F.A.; Petric, M.; Sernek, M. 2008. The influence of viscoelastic thermal compression on the chemistry and surface energetics of wood. Colloids and Surfaces. A: Physicochemical and Engineering Aspects 329: 82-86.

Liptakova, E.; Kudela, J.; Bastl, Z.; Spirovova, I. 1995. Influence of mechanical surfacetreatment of wood on the wetting process. Holzforschung 49(4): 369-375.

Loh, Y.F.; Paridah, M.T.; Hoong, Y.B.; Yoong, A.C.C. 2011. Effects of treatment with low molecular weight phenol formaldehyde resin on the surface characteristics of oil palm (Elaeis quineensis) stem veneer. Mater Des 32: 2277-2283.

Lu, J.Z.; Wu, Q. 2006. Surface characterization of chemically modified wood dynamic wettability. Wood Fiber Sci 38(3): 497-511.

Matuana, L.M.; Balatinecz, J.J.; Park, C.B. 1998. Effect of surface properties on the adhesion between PVC and wood veneer laminates. Polym Eng Sci 38(5): 765-773.

Moghaddam, M.S.; Claesson, P.M.; Walinder, M.E.P.; Swerin, A. 2014. Wettability and liquid sorption of wood investigated by Wilhelmy plate method. Wood Sci Technol 48: 161-176.

de Moura, L.F.; Hernandez, R.E. 2005. Evaluation of varnish coating performance for two surfacing methods on sugar maple wood. Wood Fiber Sci 37(2): 355-366. 
Navi, P.; Sandberg, D. 2012. Thermo-Hydro-Mechanical Wood Processing. EPFL Press, Lausanne.

Nguyen, T.; Johns, W.E. 1979. Effects of aging and extraction on the surface free-energy of Douglas-fir and redwood. Wood Sci Technol 13(1): 29-40.

Oliveira, R.M.; Brisolari, A.; Almir Sales, A.; Gonçalves, D. 2010. Wettability, shrinkage and color changes of Araucaria angustifolia after heating treatment. Materials Research 13(3): 351-354.

Pétrissans, A.; Younsi, R.; Chaouch, M.; Gérardin, P.; Pétrissans, M. 2014. Wood thermodegradation: experimental analysis and modeling of mass loss kinetics. Maderas-Cienc Tecnol 16(2): 133-148.

Piao, C.; Winandy, J.E.; Shupe, T.F. 2010. From hydrophilicity to hydrophobicity: a critical review: Part I. Wettability and surface behavior. Wood Fiber Sci 42: 490-510.

Rautkari, L.; Hughes, M.; Properzi, M.; Pichelin, F. 2010. Properties and chemical changes of surface densified wood. In: Proceeding of the $11^{\text {th }}$ World Conference on Timber Engineering, 20-24 June 2010, Trentino, Italy: Trees and Timber Institute, National Research Council pp. 235-237.

Scheikl, M.; Dunky, M. 1998. Measurement of dynamic and static contact angles on wood for the determination of its surface tension and the penetration of liquids into the wood surface. Holzforschung 52(1): 89-94.

Sernek, M.; Kamke, F.A.; Glasser, W.G. 2004. Comparative analysis of inactivated wood surface. Holzforschung 58: 22-31.

Shupe, T.E.; Hse, C.Y.; Choong, E.T.; Groom, L.H. 1998. Effect of wood grain and veneer side on Loblolly pine veneer wettability. Forest Prod J 48: 95-97.

Sinn, G.; Gindl, M.; Reiterer, A.; Stanzl-Tschegg, S. 2004. Changes in the surface properties of wood due to sanding. Holzforschung 58(3): 246-251.

Stehr, M.; Gardner, D.J.; Walinder, M.E.P. 2001. Dynamic wettability of different machined wood surfaces. $J$ Adhes 76(3): 185-200.

Tinh, N.; Pollisco, F.S.; Casilla, R.C. 1977. Effects of extraction on wettability and gluability of apitong (Dipterocarpus Grandiflorus Blanco). J Adhesion 9: 63-71.

Troughton, G.E.; Chow, S.Z. 1971. Migration of fatty acids to white spruce veneer surface during drying: relevance to theories of inactivation. Wood Sci 3(3): 129-133.

Unsal, O.; Candan, Z.; Korkut, S. 2011. Wettability and roughness characteristics of modified wood boards using a hot-press. Ind Crop Prod 34: 1455-1457.

Vázquez, G.; Galiñanes, C.; Freire, S.; Antorrena, G.; González-Alvarez, J. 2011. Wettability study and surface characterizacion by confocal laser scanning microscopy of rotary-peeled wood veneers. Maderas-Cienc Tecnol 13(2): 183-192.

Walinder, M.E.P.; Johansson, I. 2001. Measurement of wood wettability by Wilhelmy method. Part 1. Holzforschung 55(1): 21-32.

Wei, S.; Shi, J.; Gu, J.; Wang, D.; Zhang, Y. 2012. Dynamic wettability of wood surface modified by acidic dyestuff and fixing agent. Appl Sur Sci 258: 1995-1999. 